\title{
6th SETAC-Europe Meeting: LCA - Selected Papers
}

\author{
Editor: Allin $\lambda$ strup JENSEN \\ Energy and Environment, dk-TEKNIK, Soborg, Denmark (see Fditorial, p. 121) \\ Co-Editors: Roland CimT \\ Centre for Fenvirommental Strategy, University of Surrey, Guildford, U.K. \\ Patrick Holstiztek \\ Gruppe Fnergic-Stoffe-Umwclt (ESU), Institut für Energietechnik, ETH-Zentrum, Zürich, Switzerland \\ Dennis Postl.:THWATt: \\ Unilever Rescarch Port Sunlight Laboratory, East Bebington, Wirral, U.K.
}

\section{LCA Use in Swedish Industry}

\author{
Henrikke Baumann \\ Technical Finvironmental Planning, Chalmers University of Technology, S - 41296 Cöteborg, Sweden
}

\begin{abstract}
A study of industrys use of I.CA has been performed as a special analysis of the Business finvirommental Barometer (B.F.B.). The B.F...B. is an international questionnaire survey on industry's environmental management practices (LC.CA included), repeated every two years. The first round in 1993 included the Nordic conntries. The 1997 round will indude cight European countries. This analysis intends to describe industry's I.CA use as such (c.g. active industrial sectors, applications, changes over time) and differences between companies working with I.C.A and those not working with I.CA. The survey indicates that industry is in the process of internalising LCA knowledge, although most companies are still in the learning phase. 1.CA companies have more developed environmental management systems than non-l.CA companies. A company's LCA use seems to be a competitor-driven activity, judging from LCA distribution among industrial sectors.
\end{abstract}

Abbreviations: LC.A - life cycle assessment; L.Cl - life cycle inventory analysis; BEB - the Business Environmental Barometer

Keywords: Life cycle assessment (LCA); Business Environmental Barometer; statistical survey; environmental management

\section{Introduction}

The methodological choices regarding LCA are manyfold: LCI, full LCA, or screening LCA? Type of functional unit, allocation methods, interpretation methods? The most appropriate methodological choices, however, can be deduced from the decision-making context in which the LCA is used (BAUMANN, 1995). To develop an LCA methodology that considers the requirements of various decision-making situations, it is important to know what typical decision situations are possible. This was the starting point of an analysis of data from the Business Environmental Barometer
(B.E.B.), i.c. an international survey on environmental management practices in industry. The survey offers an alternative way to identify areas for methodological development as well as a general investigation of the role of LCA in decision making in industry. Being international, the survey reveals whether I.CA usc is evolving similarly in different countries. In this respect, efforts to promote LCA or the impact of LCA-related regulations such as the EU ecolabelling scheme are interesting to discuss. Furthermore, a picture of how LCA use varies in industry can provide useful information for descriptions of LCA methodology better adjusted to the target groups.

\subsection{Other surveys}

Apart from the B.E.B., there are quite a number of surveys - many of them are Swedish - that concern companies' experience with LCA and their opinions on LCA methodology (IVA, 1991; FINNVEDEN \& LINDFORS, 1992; RYDING, 1992; KarLson, 1993; OMrCen, 1994; RUbiK \& BaumGARTNER, 1992). The surveys performed by FTU-VITO in Belgium (1995) are informative, describe LCA practices and the trend of the LCA debate, but their statistical sampling differs greatly from the Barometer, a feature which makes the comparison difficult. Surveys like the 'Barometer' are intended to representatively map what is actually happening in industry. There are other surveys, more similar to the Barometer, which concern the way LCA can be related to other environmental activities within the companies. The survey by ARNFalk \& THIDELl (1991) aimed at mapping environmental practices in the Swedish manufacturing industry is one example. The survey by Sullivan $\&$ EHRENFELD (1992) investigated LCA and LCA-related practices in large manufacturing companies in the USA. A similar survey has been performed in Germany by GROTZ \& SCHOLL (1996) as well. 


\section{Methods: Survey and Research Design}

The survey has the form of a questionnaire. Some of the questions relate specifically to LCA. In this paper, only results concerning the use of LCA are presented. For more information from B.E.B. results, see WOLFF et al. (1995).

The survey, which will be repeated every two years, was first performed in 1993. It involved the Nordic countries (Sweden, Norway, Finland and Denmark). The second round, carried out in 1995, was extended to include Switzerland. Belgium, Great Britain and Spain are about to join in the third round. The survey is organized and has been carried out by researchers from business schools in the participating countries.

In the 1993 round, the sample consisted of only the companies listed on the Stock Exchange. In the second round, two samples were used: the listed companies and a random sample of companies with more than ten employees.

The questionnaires consist of Core Questions which are the same in all participaring countries. In addition, each country can decide which other questions are useful and should be included. LCA questions belong to the additional questions. Questionnaires are sent to managing directors in both samples, and to environmental managers in listed companies. The questionnaire for the managing directors in the random sample included only one question about LCA: do their companies use LCAs or not? The questionnaire to environmental managers in the listed companies was more detailed and included questions about LCA applications, and how often and by whom the LCAs were carried out.

\section{Analysis}

\subsection{Issues studied}

The goal of the first part of the analysis is to describe an industry's LCA activity as such, e.g. variations in LCA occurrence and applications among industrial sectors, changes over time, and types of LCA. The second part of the analysis investigates whether companies involved in LCA activities operate under special conditions. Given the number of countries, samples and questionnaire versions, it is difficult to make a comprehensive analysis. I have chosen to focus on the responses from environmental managers in listed Swedish companies and on the Swedish and Swiss random samples, although a few results from the other countries are included as well. Denmark is excluded as there were no LCA questions in their questionnaires. There are some variations in the way the participating countries have carried out their random sampling (e.g. size of sample) which is why country comparison must be made with caution.

The part of the analysis concerned with conditions for LCA activity is made by dividing each sample into two groups, LCA companies and non-LCA companies. The question of whether or not a company uses LCA is correlated to other questions describing perceptions and organisation in the company. Aspects identified as potentially characteristic of LCA use are: perception of pollution problems along the life cycle, perception of stakeholder pressure and organisation of the environmental management system.

\subsection{Statistical analysis}

Correlation between two variables have to be tested against the probability ( $p$ ) that the relationship is not coincidental. Since the choice of statistical test method depends on the type of data involved, the type of data provided by the response options has to be considered. Statistical tests methods used include:

- Contingency table analysis when both answering options are categories, such as 'LCA / no LCA' and ind ustrial sectors;

- unpaired comparison tested with the Mann-Whitney U test when there are two groups of respondents and the response option is on a scale from 1 to 5 .

Contingency table analyses determine whether there is a relationship between two categorical variables, e.g. LCA applications and industrial sectors. By cross-tabulating two sets of categorical data and comparing observed frequencies to the expected value, it is possible to see if the two variables are independent. The chi-square test for independence is used to see which groups have more/fewer observations than would be expected. A low chi-square value and a high $\mathrm{p}$ value indicate that variables are independent, while large chi-square and low $p$ indicate the possibility of a relationship (Abacus Concepts, 1992; Ric1:, 1995).

When comparing two groups of respondents such as I.CA companies and non-L.CA companies, the underlying data distribution needs to be considered. The Mann-Whimcy U test is used to analyse data for which the underlying distribution is not assumed. For many other statistical tests, data must come from a normal distribution. The Mann-Whitney $U$ test tests the hypothesis that the distribution of the two groups are the same $(p<0.01$ indicates a significant difference between the two groups). The Mann-Whitney $U$ test employs a method that sequentially ranks the observations to test hypotheses and is therefore resistant to outliers (Abacus Concepts, 1992; Rice, 1995).

\section{Results}

Data from the participating Barometer countries have been compiled for this analysis. Many data are found in the respective national reports. The Norwegian Barometer is presented by YTTERHUS et al. (1994); the Swiss Barometer by BELZ \& DYLLICK (1996); the Finnish Barometer by Lovio and Kuusisto (1996).

\subsection{Response rates}

The response rate varies depending on the respondent group, but the overall response to the survey must be considered good, as response rates are $50 \%$ or more. 100 returned questionnaires represent $67 \%$ of the Swedish sample $(\rightarrow$ Table 1). For the comparison between 1993 and 
199.5, the analysis had to focus on manufacturing companies because LCA questions were not directed at service companies until 1995. There are as yet no results from the Norwegian listed companies for 1995.

Table 1: Number of responses and response rates

Listed companies - manufacturing firms
\begin{tabular}{l|c|c|c}
1993 & Sweden & Finland & Norway \\
1995 & $100(67 \%)$ & $67(64 \%)$ & $39(80 \%)$ \\
$110(52 \%)$ & $31(48 \%)$ & n.d.
\end{tabular}

Random sample ( $>10$ employees)

\begin{tabular}{l|c|c|c}
1995 & $\begin{array}{c}\text { Sweden } \\
310(49 \%)\end{array}$ & $\begin{array}{c}\text { Finland } \\
75(52 \%)\end{array}$ & $\begin{array}{c}\text { Switzerland } \\
262(52 \%)\end{array}$ \\
\hline
\end{tabular}

\subsection{LCA activity in industry}

\subsubsection{How common is LCA in industry?}

Four observations can be made based on the data presented in Table 2:

1. LCA is more common in the larger listed companies than in the generally smialler companies of the random sample;

2. LCA is more common in the manufacturing industry than in the service sector;

3. There was a slight increase in LCA use between 1993 and 1995;

4. LCA was less common in Sweden than in the other countrics. This last observation is somewhat unexpected (at least for Swedes) and we can only speculate on the causes.

Table 2: Occurrence of I.CA

\begin{tabular}{|c|c|c|c|}
\hline \multicolumn{4}{|c|}{ Listed companies - manufacturing firms } \\
\hline & Sweden & Finland & Norway \\
\hline $\begin{array}{l}1993 \\
1995\end{array}$ & $\begin{array}{l}20 \% \\
37 \%\end{array}$ & $\begin{array}{l}38 \% \\
48 \%\end{array}$ & $\begin{array}{l}40 \% \\
\text { n.d. }\end{array}$ \\
\hline \multicolumn{4}{|c|}{1995 Random sample } \\
\hline & Sweden & Finland & Switzerland \\
\hline $\begin{array}{l}\text { All firms } \\
\text { Manufacturing } \\
\text { Service }\end{array}$ & $\begin{array}{c}12 \% \\
18 \% \\
7 \%\end{array}$ & $\begin{array}{l}28 \% \\
\text { n.d. } \\
\text { n.d. }\end{array}$ & $\begin{array}{l}25 \% \\
35 \% \\
14 \%\end{array}$ \\
\hline
\end{tabular}

A sectorial breakdown of LCA activity in Swedish listed companies is presented in Figure 1. It shows that LCA is very common in the forestry/pulp \& paper industry in Sweden $(71 \%)$. The high response rate for the forestry sector ( $82 \%$ in 1993) implies that nearly all the companies in this sector work with LCA. Another sector with noticeable LCA activity is the metal and engineering sector, where the largest number of LCA active companies are found. LCA, however, is not as common in the engineering sector as in the forestry sector. For other sectors, there is a seemingly random occurrence of LCA.

A comparison of selected industrial sectors in the Swiss and Swedish random samples is presented in Table 3 . The comparison shows that the food industry, graphical / packaging industry and retail are more LCA-active in Switzerland

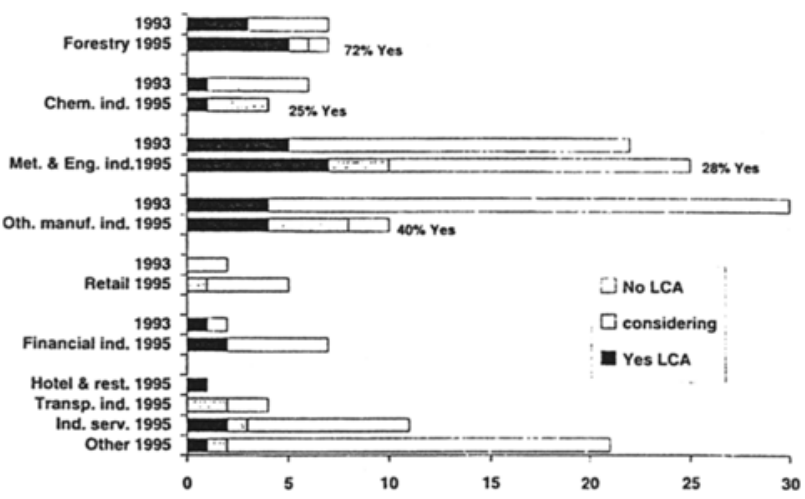

Fig. 1: Number of Swedish listed companies using LCA per industrial sccrors in 1993 and 1995. Service industry uas not included in the survey of 1993. Definition of the category 'Ohter manufacturing industry" is different for 1993 and 199.5

than in Sweden. For additional comparison, most LCA active industries in Finland are the food processing industry and the forestry industry.

Table 3: Number of I.CA-acrive companies / sector in Swiss and Swedish random samples

\begin{tabular}{l|c|c}
\hline 1995 & Switzerland & Sweden \\
\hline Food ind. & 12 (out of 20) & 1 (out of 4 ) \\
Graph./pack. ind. & 12 (out of 28) & 2 (out of 10) \\
Retail & 7 (out of 26) & 6 (out of 49) \\
Chemical ind. & 8 (out of 12) & 4 (out of 9) \\
Forestry ind. & 0 (out of 3) & 4 (out of 10) \\
\hline
\end{tabular}

\subsubsection{Types of LCA}

The most common application of LCA is for an analysis of the company's own product. This and other LCA applications in Swedish listed companics is presented in Table 4. The ranking of applications remained the same betwen 1993 and 1995, apart from 'analysis of line of business' which is a more company-strategic use of LCA.

Table 4: LCA applications in listed Swedish companies

\begin{tabular}{r|r|l}
\hline 1993 & 1995 & \\
\hline 12 & 14 & analysis of own product \\
8 & n.d. & to learn about LCA \\
6 & 11 & product development \\
6 & 11 & for external use (marketing, labelling...) \\
5 & 9 & process development and optimisation \\
5 & 9 & choice of suppliers and raw materials \\
5 & 5 & in-training programmes \\
3 & 8 & analysis of line of business \\
3 & 6 & to meet authorities' demands \\
\hline
\end{tabular}

Cross-tabulating applications and industrial sectors shows one marked difference between the forestry and the engineering sectors. Marketing applications are mainly found in the forestry industry ( 4 out of 5 , and 1 out of 7 , respectively). It is also interesting that none of the engineering companies use LCA in purchasing / to choose between sup- 
pliers and that only 2 out of 7 engineering companies state that they usc LCA for product development.

In Sweden, LCAs are mostly carried out as quantitative analyses, sometimes supplemented with qualitative information ( 18 out of 22 in 1995). Qualitative studies as such are rare in Sweden (4 out of 22 in 1995), in contrast to the situation in Finland where half of the LCAs are qualitative analyses (10 out of 21 in 1995). If qualitative LCAs are not regarded as 'proper' LCAs in Sweden, this could be one explanation of why LCAs are less common there than in other Barometer countries. Also, I have understood that there is a double meaning to the term 'Oekobilanz' in the German language - it stands both for LCA and for mass balances for a industrial site/company. This might account for the relatively high occurrence of LCAs in Switzerland.

\subsubsection{Who carries out the LCA?}

There seems to be a trend that LCAs are becoming an internal affair for the companies more and more. As shown in Table 5, externally made LCAs are becoming less and less common. An earlier study by RYDINC; (1992) showed that 7 out of 10 companies used consultants for their LCAs in 1991. In the Swedish companies, it is usually the R\&D/Product development departments that conduct LCAs. Marketing departments are not yet involved, but might be in the future. Among those companies planning for I.CAs, three plan to place the L.CA work with their marketing departments.

Table 5: Where L.CAs are carried out in Swedish I.CA-ictive listed companics

\begin{tabular}{r|r|l}
\hline 1993 & 1995 & LCAs are carried out: \\
\hline 9 & 16 & Internally, by: \\
& 12 & R \& D / Product development \\
& 3 & Environmental dept. \\
& 2 & Purchasing \\
& 2 & Production \\
4 & 4 & Internally \& Externally in cooperation: \\
& 4 & Industry cooperation \\
& 1 & Consultant together with R \& D / Product development \\
2 & - & Externally \\
\hline
\end{tabular}

\subsubsection{How often are LCAs performed?}

The question was put differently in 1993 and 1995, thus complicating straightforward comparison. In 1993, where the response options were seven frequency levels ranging from ' $>1 /$ month' up to ' $<1 /$ year', LCAs were conducted seemingly seldom - 12 companies out of 14 replied ' 1 /year'. Only 2 companies, whose reply was '>1/month', seem to conduct LCAs on a regular basis. This is to be compared with 1995, where 8 out of 23 replied that LCAs were conducted 'to a large extent'. The remainder (15) only conducted LCAs 'to a small extent'. This indicates that there could be a slight increase in the number of companies working with LCAs on a regular basis.

\subsection{Comparison of LCA companics and non-LCA companies}

In order to find out the necessary conditions for LCA work, a comparison has been made between companies working with LCA and those not working with LCA.

\subsubsection{Pollution along the Life Cycle}

The hypothesis was that companies experiencing problems with pollution along the life cycle were more LCA-active. An analysis shows that there is no difference in how LCAactive companies perceive their pollution problems as compared with the non-LCA companies (Mann-Whitney $U: p$ " 0.01). This applies to both listed companies and those in the random sample in Sweden. The same observation also seems to be valid for Switzerland, although the Swiss data have not undergone strict statistical testing.

\subsubsection{Stakeholder pressure}

The respondents are asked to indicate experienced stakeholder pressure concerning environmental issues on a scalc from 1 to 5 (low to high). Examples of stakeholders are employees, financial institutions, competitors, customers, environmental organisations and media. Considering the listed Swedish companies, there is no significant difference between how LCA companies and non-LCA companies experience stakeholder pressure (Mann-Whitney U: p " $0.01)$. In the Swedish random sample, it seems that I.CA companies experience a higher pressure from customers and owners than do non-L.CA companies $(p=0.01)$. Nevertheless, the different results for listed companies and the random sample imply that this correlation needs to be tested against company size.

In Switzerland, I.CA companies might experience higher pressure from the media, consumer organisations, international legislation and employees than do non-LCA companies. Again, the Swiss dara must be subjected to betrer statistical testing before any conclusive statements can be made.

\subsubsection{Environmental management system}

The respondents were asked to indicate whether or not various elements of environmental management systems were present in their companies. Examples are environmental policy, environmental audits, measurable (quantitative) environmental goals, public environmental reports, environmental-related market analyses and environmental product development. In this case, there is a significant difference between the LCA companies and the non-LCA companies ( $\mathrm{p}$ « 0.01 ) with regard to how well their environmental work is organised. Thus, LCA seems to require a well-developed environmental management system. This finding applies both to Swedish listed companies and the Swedish random sample. The same observation also seems to apply to Switzerland.

\section{Conclusions and Discussion}

Suspicions that LCA is a passing fashion and will be given up by industry unless methodological problems are re- 
solved, are voiced from time to time. However, this survey shows that LCA is increasingly becoming an inside-thecompany activity which, in turn, indicates that companies are taking LCA seriously, by investing the time and competence to work with the LCAs themselves. Judging from the trends in the data, a process of internalising LCA knowledge is going on, although most companies are still in the learning phase. Companies seem to start with an externally made LCA before they carry out a study on their own and, in most cases, it concerns an analysis of the company's own product. In addition, LCA is becoming a more regular activity within the companies. This shows that LCA is slowly becoming an established tool, and that the real LCA boom is probably yet to come.

The observation that the most common type of LCA is a study of the company's own product, leads to a conclusion regarding an area for methodological development. Analysis of the company's own product implies the use of a stand-alone, exploratory type of LCA, which is used to generate alternatives. Another type of LCA which is used for comparing formulated alternatives is the comparative LCA . In decision theory terms, these two types represent very different phases in the decision-making process, or even different types of decision making, and can be exemplified through decision-making in product development and purchasing, respectively. LCA methodology does not yet formulate the requirements for these two types of LCA.

Another conclusion is relared to the occurrence of LCA in industry. LCA use is not evenly spread among the industrial sectors. Some sectors seem to be very active, others not at all. Also, the most active sectors vary from country to country. It therefore seems that LCA is a competitor-driven activity as described by SPENCER (1986). With competitors assessing and copying one another, the role of the branch organisations would be interesting to study with regard to how this LCA use is distributed.

Questionnaire surveys can economically describe features of large numbers of organisations. However, there are two limitations. Statistical analysis cannot explain why correlations exist. In addition, it is difficult to eliminate all external factors which could possibly have caused the observed correlation. PeTTIGREw (1985; in EASTERBY-SMITH et al., 1988 ) suggests longitudinal research, which focuses on a small number of organisations over long period of times, to remedy these disadvantages. Future rounds of the Business Environmental Barometer in combination with field studies will show whether or not the conclusions presented here will hold up.

\section{Acknowledegements}

This survey would not have been possible without the assistance of a large number of colleagues in the Barometer network who have passed on sets of their national data to me. I particularly wish to thank Rolf WOLFF, Lars STRANNEGÄRD and Petra ADOLFSSON at GRI for including my LCA questions in the survey and discussing research design and results, and Peter WESSMAN at the department of Statistics, Göteborg University, for valuable advice on statistical testing. The financial support of the Swedish Waste Research Council (AFR) is also gratefully acknowledged.

\section{References}

Abacus Concepts (1992). StatView. Berkeley, Ca, USA: Ahacus Concepts, Inc.

ArNFA.K, P\& A ThIDFLL. (1992). Miljöarbete inom svensk tiliverkningsindustri - Myt eller verklighet? Department of industrial economics, University of Lund, L.und, Sweden. (Environmental work in Swedish manuficturing industry - Myth or reality?)

Br.I.Z, F \& T Drit.ICK (1996). Unweltmanagement-Baroneter $1995 / 96$. Swiss Environmental Barometer (forthooming)

DifFlinkat:H, JR (1993). Lifecycle Economic Analysis: A Case Study Examination of its Role in Organizational Decision Making. IBIS working paper. Wellesley, Mass., USA: IBIS Associares, Inc.

EAstrkbr-SurTh, M., R THORPl: \& A LoWE (1991). Management Research. An Introduction London, UK: Sage Publications

FinNVFH) - demands and expectations". In Product L.ife Cycle Assessinent Principles and Methodology Nord 1992:9. Copenhagen, Denmark: Nordic Council of Ministers

FTU-VITO (1995). Les Ecobilans: utilité et limites d'un outil de concertation et d'aide a la decision. Fondation Travail-Université (FTU), Vlaamse Instelling voor Technologisch Onderyock (VITO) and Institur für Ökologische Wirtschaftsforschung. Brussels, Bclgium: Fondation Roi Baudouin. (Ficobalances: uses and limitations of a tool for consultation and decision support.)

Cirolz, S \& (i S.tHon.1. (1996). Application of I.CA in (ierman Industry - Results of a Survey. Institut für Ökologische Wirtschaftsforschung (IOW). Int. J. I.CA (in press)

KaRI soN, l. (1993). Produktekologiprojckter. Simmanstiilning av deltagarnals erfarenheter. ABB Corporate Research, Västerias, Sweden. (Product Ficology Project. l'articipants' Experiences. Paper put together for a project meeting Dec 1, 199.3.)

Lovko, R \& P-C Killsisro (1996). "Studies on environmental comperitiveness of Finnish companies in the mid 1990k'. In Industry and

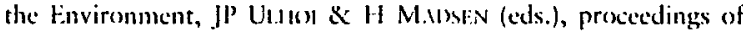
the 3rd Conference of the Nordic Business Environmental Man:agement Network, Narch 28-30, 1996, Aarhus, Demulark

OMreien (1944). The Product Beology Project - Creating Prerequisites for en Finvirommentally Adjusted Produce Development. Paper presented at Business and Environment, Nordic Network Conference, Oslo, Norway, December 1-2, 1994 / J Cleaner Production, vol 3, no $1-2$, pp $89-94$

Rick, J.A. (1995). Mathematical Statistics and Data Analysis, 2nd ed. Bulmont, Ca., USA: Duxbury Press

Royal Swedish Academy of F.nginecring Sciences (1992). Miljöanpassad produktutweckling. En kartläggning av svensk industri IVA report 394. Stockholm, Sweden. (Environmental product development. A survey of the Swedish industry)

RUM⿻, $F$ \& T BA(NikiarTNFR (1992). Evaluation of Ecobalances. EUR14737-EN, SAST project no 7. Luxemburg: Commission of the European Communities

Rrding, S-O (1993). International Experiences of EnvironmentallySound Product Development Based on Life Cycle Assessment (LCA). Stockholm, Sweden: Federation of Swedish Industries

UDO DE. HAEs, HA (1993). Applications of life cycle assessment: expectations, drawbacks and perspectives. J Cleaner Production, vol 1, no 3-4, pp 131-138

SPENCER, JC (1989). Industry Recipes: An Enquiry into the Nature and Sources of Managerial Judgment. Cambridge, Ma., USA: Basil Blackwell

SULLIVAN, MS \& JR EHRENFEL.1) (1992). Reducing Life-Cycle Environmental Impacts: An Industry Survey of Emerging Tools and Programs. Total Quality Environmental Management, vol 2, no 2, pP 143-157

WolfF, R et al. (1995). The Nordic Business Environmental Barometer. Oslo, Norway: Bedriftsokonomens forlag

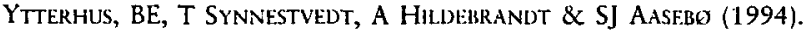
The Norwegian Business Environmental Barometer 1993. Business Attitudes, Responses and Actions to the Environmental Challenges. Department of Business Economics Working paper 1994/11. Sandvika, Norway: Norwegian School of Management 